\title{
CIENCIA Y MARXISMO EN LA ARQUEOLOGÍA MEXICANA
}

\author{
Jesús Carlos Lazcano Arce
}

Toda la historia de la sociedad humana, hasta el día, es una historia de lucha de clases. Libres y esclavos, patricios y plebeyos, barones y siervos de la gleba, maestros y oficiales; en una palabra, opresores y oprimidos, frente a frente en siempre, empeñados en una lucha ininterrumpida, velada unas veces, $y$ otras franca $y$ abierta.

Marx y Engels: Manifiesto del Partido Comunista

\section{RESUMEN}

Para el conocimiento de múltiples hechos sociales la antropología y en particular la arqueología ha hecho uso de diversas posturas filosóficas. A pesar de la idea simplista y errónea de "pasado de moda" o "no es arqueología, es teoría", el materialismo histórico también conocido como marxismo ha sido una fuente invaluable para la explicación de las sociedades humanas del pasado y actuales. En México, sus creadores y usuarios han logrado proponer nuevas categorías y conceptos de análisis y, al mismo tiempo, dar contrastación de sus postulados con la realidad social pretérita que se pretende conocer.

Palabras clave: Teoría arqueológica, marxismo, ciencia, arqueología mexicana.

\section{RESUMO}

Para o conhecimento de muitos eventos sociais, a antropologia e, em particular, a arqueologia tem feito uso de várias posições filosóficas. Apesar da ideia equivocada e simplista de "antiquado" ou "não é arqueologia, é teoria", o materialismo histórico, também conhecido como marxismo, tem sido uma fonte inestimável para a explicação das sociedades humanas passadas e presentes. No México, seus criadores e usuários conseguiram propor novas categorias e conceitos analíticos e, ao mesmo tempo, contrastar seus postulados com a realidade social passada que pretendem conhecer.

Palavras-chave: Teoria Arqueológica, marxismo, ciência, arqueologia mexicana.

${ }^{1}$ Investigador de tiempo completo del Instituto de Investigaciones Antropológicas de la Universidad Nacional Autónoma de México. E-mail: clazcano@humanidades.unam.mx.

\begin{tabular}{|l|l|l|l|l|l|l|} 
(C) Rev. Arqueologia Pública & Campinas, SP & v.9 & N $^{\circ}$.1(11) & p.3-17 & Jan-Jun/2015 & ISSN 2237-8294
\end{tabular}




\section{ABSTRAC}

To the knowledge of many social events including anthropology and archeology it has made use of various philosophical positions. Despite the simplistic and erroneous "old fashioned" or "not archeology, it is theory" thought historical materialism also known as Marxism has been an invaluable source for the explanation of human societies past and present. In Mexico its creators and users, have managed to propose new analytical categories and concepts and at the same time give its principles contrasting with the bygone social reality that seeks to know.

Keywords: Archaeological Theory, Marxism, Science, Mexican archeology.

\section{INTRODUCCIÓN:}

Antoine-Laurent de Lavoisier fue un químico, biólogo y economista francés del siglo XVIII que junto con su esposa la científica Marie-Anne Pierrette Paulze, son considerados los creadores de la química moderna por sus estudios sobre la oxidación de los cuerpos, el fenómeno de la respiración animal, el análisis del aire, la ley de conservación de la masa, la teoría calórica y la combustión. Una de sus características más destacadas fue la formulación de teorías e hipótesis sobre la oxidación y la separación de elementos sin que perdieran su masa. Para corroborar sus propuestas realizaba infinidad de experimentos y mediciones precisas. Como ellos, podríamos citar infinidad de investigadores que en las disciplinas naturales o también llamadas "ciencias duras" destacan por sus aportes al conocimiento científico. Bajo esta perspectiva podemos preguntarnos, ¿las ciencias sociales o disciplinas humanas poseen este mismo rigor? ¿existe en la realidad social regularidades que deben de ser conocidas y explicadas?. Con la precisión que consideramos se efectúa la investigación en las ciencias naturales de igual modo es posible preguntar ¿la antropología y en particular la arqueología ¿busca obtener el mismo tipo de conocimiento científico como el de las disciplinas naturales?.

\section{LA ARQUEOLOGÍA COMO DISCIPLINA HUMANA Y DE LAS CIENCIAS SOCIALES}

Para establecer que tipo de conocimiento generara la arqueología debemos remontarnos a los inicios de la disciplina. Recordemos que durante la época del expansionismo económico, colonización y exploración europea se descubren sociedades que no comparten las características reconocidas para el mundo occidental. La 
sistematización de estos descubrimientos se inicia a mediados del siglo XIX. El resultado de este nuevo conocimiento establece que lo europeo (definido a priori como civilización) posiblemente se dio por modificaciones evolutivas antiguas. Al mismo tiempo se dan comparaciones entre los nuevos grupos y sociedades con lo cual se realizan estudios etnográficos en una enorme variedad de temas como la escritura, el parentesco, la religión, la arquitectura, etcétera. Aspectos de los cuales se buscaba conocer en dónde y cuándo habían aparecido por vez primera, esto en virtud de que se consideraban elementos evolutivos y que las sociedades, todas, habían pasado por diferentes cambios.

En este inicio de la disciplina, lo evolutivo se toma directamente de las propuestas establecidas en las ciencias naturales. En este primer momento la arqueología, considerada hasta ese momento una rama de la historia, aporta muchos datos con los cuales se comienzan a dar las primeras secuencias evolutivas. Sin embargo, el quehacer de la arqueología se limitaba al estudio y descripción casi de manera exclusiva, de los restos materiales producidos en un determinado lugar y tiempo específico, tipo de estudio que permaneció durante mucho tiempo y que ahora se le denomina Histórico Cultural o Particularismo Histórico, cuyos iniciales aportes no están en discusión.

En los años sesenta del siglo pasado dentro del mundo académico anglosajón, la polémica que generaban estas preguntas sobre la relación entre la ciencia y la antropología y, con la intensión de superar la descripción, la clasificación y la mera comparación que se daba en las investigaciones arqueológicas, el investigador Lewis R. Binford (1968, 1977) estableció como alternativa que se utilizara el método de investigación científica que establecía Carl G. Hempel, filósofo de la ciencia cuya propuesta era el modelo nomológicodeductivo. Binford, al retomar este sistema conformó la llamada Arqueología Procesual o Nueva Arqueología. Sin embargo, existió de manera inmediata una crítica en la cual uno de sus discípulos Kent V. Flannery, profesor de la Universidad de Michigan, señaló la inconsistencia de esta propuesta. En México esta concepción no creo muchos adeptos y en la Escuela Nacional de Antropología e Historia, creada en los años cuarenta y principal institución de formación de antropólogos y arqueólogos, el profesor Manuel Gándara estableció con su texto "La vieja "nueva arqueología"” la incompatibilidad de esta visión neopositivista. De cualquier modo y en su momento, fueron pocos los que se agruparon en torno a la relevancia de discutir el tipo de conocimiento que la disciplina arqueológica generaba o debía generar.

Pero entonces ¿cuál fue la alternativa a esta disyuntiva? Como veremos más adelante M. Gándara Vázquez (2008) no solo determina la relevancia de esta discusión 
para el quehacer de la arqueología mexicana, sino también para dar mayor certeza a los propios postulados de la arqueología marxista que se desarrolla en nuestro país.

\section{EL MATERIALISMO HISTÓRICO Y LA ARQUEOLOGÍA}

El materialismo histórico o pensamiento marxista generado a mediados del siglo XIX, principalmente por Karl Marx, Federico Engels y Vladimir I. Lenin, nutrido y sustentado en diversas escuelas, es una teoría general en la cual se establece que el desarrollo y devenir de las sociedades se ha dado a partir de las contradicciones que han tenido las relaciones sociales de producción, es decir, que desde su origen, las sociedades humanas para reproducirse biológica y socialmente se han organizado de diversas formas y, cuando esta organización llega a una determinada fase de desarrollo, entra en contradicción transitando a un nuevo modo de producción en cuyo seno se encuentran las fuerzas productivas y las relaciones de producción y, en éstas, la propiedad. Aunado a esto, su ámbito ético-moral establece que se debe de alcanzar una sociedad sin clases en la que no exista propiedad privada sobre alguno de los elementos que constituyen a las fuerzas productivas: fuerza de trabajo (energía humana) y medios de producción. Estos planteamientos, aquí resumidos (MARX, 1991) determinan el curso del desarrollo sociohistórico y se establece como una alternativa de pensamiento que diera cuenta del devenir histórico de las sociedades.

Desde este punto de vista, el análisis del pasado y de las transformaciones que han tenido las sociedades se establece a través de la existencia de diferentes modos de producción, distinguibles históricamente: Comunismo primitivo, modo de producción esclavista, modo de producción feudal, modo de producción capitalista (actualidad).

Bajo la concepción señalada también el marxismo establece el tipo de sociedad que a futuro se debe aspirar: el modo de producción socialista y el comunista.

Uno de los precursores en utilizar al materialismo histórico en el quehacer arqueológico fue el australiano Vere Gordon Childe, también crítico del enfoque histórico cultural. Bruce Trigger (1980) nos dice de Childe:

reconocía que el cambio de los grupos no se debía a la tecnología sino a la organización social. Los arqueólogos decía, tenían por tanto, la obligación no solo de describir los restos arqueológicos sino también de reconstruir las sociedades que los habían producido. Childe intentó formular explícitamente de una manera más marxista- explicaciones sobre el cambio cultural, dirigidas no al conocimiento tecnológico como principal motivador, sino a las instituciones sociales, políticas y económicas y al papel que 
desempeñaron en la realización del cambio. Childe progresó de una comprensión simplista del papel desempeñado por la tecnología al influenciar el comportamiento humano, a los sofisticados puntos de vista que sostuvo en la última década de su vida.

Su introducción al marxismo como una herramienta útil para la interpretación de los datos arqueológicos resultó de su "iniciación" a la arqueología soviética a principios de 1935. Lejos de rechazar al marxismo como base para analizar datos arqueológicos, inició un diálogo altamente productivo entre las teorías marxistas y los datos arqueológicos. Esta operación hizo que el enfoque marxista fuera más vital que nunca para su trabajo y convirtió a Childe en un importante pensador marxista (TRIGGER, 1980).

A lo largo de su historia en México, la arqueología se ha concebido de distintas formas, lo que ha producido que se tengan diversas caracterizaciones con respecto a los grupos y sociedades del pasado que se estudian. A este respecto el erudito investigador Román Piña Chan (1970) nos dice:

El propósito de la arqueología es reconstruir la cultura de las sociedades desaparecidas, la conducta del hombre del pasado; y para lograrlo necesita excavar, recoger, observar, para luego analizar y ordenar, describir, explicar, integrar y sintetizar, procedimientos que constituyen su método (PIÑA CHAN, 1970:3)

El investigador Manuel Gándara (1982) señala:

La arqueología es una ciencia social que explica la variabilidad cultural, tal como ésta se expresa en el lapso total de la existencia del hombre. Los materiales arqueológicos tienen una organización que debe de reflejar la operación de diferentes subsistemas y su mera descripción no constituye un estudio del pasado (GÁNDARA, 1982:65-66)

Esta variedad, tanto en las definiciones sobre el concepto de la arqueología como en el resultado de los mismos estudios, responde a la amplia gama de "corrientes", "escuelas", "tradiciones" o en su caso a "posiciones teóricas", en las que se han basado los investigadores. A este respecto el investigador Ignacio Bernal (1979) señaló:

Si se han dado tantas y tan distintas definiciones de arqueología, que indican sin lugar a dudas las múltiples formas en que ha sido vista y puede entenderse, se debe a las teorías detrás de ella, a lo que podríamos llamar la filosofía de los distintos arqueólogos y épocas (BERNAL, 1979:7) 
Desde los años sesenta del siglo pasado la posición teórica sustentada en los postulados del marxismo en la investigación arqueológica mexicana se denominó arqueología social latinoamericana, definida así en virtud de los aportes que diversos arqueólogos marxistas de Venezuela, Perú, República Dominicana, Chile y México entre otros, la conformaron. Esta posición teórica ahora denominada Ameroibérica tuvo sus precursores como Ricardo Latcham y Emilio Choy, posteriormente llegan los escritos de L. H. Morgan y tiempo después de V. Gordon Childe. Investigadores como Mauro Olmeda y Pedro Armillas se ven también influenciados.

En los años setenta se efectúan reuniones y congresos internacionales con los que se va conformando esta posición; en estos mismos años en México van destacando antropólogos de alto nivel como Carlos Navarrete y Piña Chan, en desacuerdo con muchos de los postulados de la recién llegada "Nueva Arqueología" propuesta por Binford con la cual la arqueología Ameroibérica tiene algunas coincidencias (BATE, 2000:6)

Autores como Mario Sanoja, Iraida Vargas, Marcio Veloz y en México Felipe Bate, Julio Montané sí como Manuel Gándara son los continúan sustentando esta teoría, algunos más son ahora profesores en la Escuela Nacional de Antropología e Historia y otros se encuentran en el Instituto de Investigaciones Antropológicas de la Universidad Nacional Autónoma de México.

Sin pretender dar cuenta detallada de su historia ya descrita por Bate (1998) y retomada por otros autores, si queremos señalar que la posición teórica de la arqueología Ameroibérica es una alternativa a posturas eclécticas o puntos de vista subjetivos idealistas como los contenidos en la arqueología posmoderna. Ambas posturas que en muchos casos van de la mano han creando un eclectisismo ramplón. Asimismo, trasciende el pensamiento histórico cultural que todavía está muy arraigado en la arqueología mexicana. De igual modo se aleja de posicionamientos básicos de interpretaciones analógicas de sentido común y de razonamientos sobre la naturaleza buena o mala del ser humano. Asimismo no acepta posturas "voluntaristas o de toma de decisión", en las cuales las sociedades humanas, "al ser muy complejas y cuya acción es voluble no tiene regularidades"

De esta manera y dando respuesta a las primeras interrogantes de este escrito, la arqueología Ameroibérica establece, con relación al tipo de método y conocimiento que debe de generar, una postura unificacionista metodológica en la cual se establece que el método es uno y que solamente hay una sola forma de generar conocimiento y de explicar la realidad, en contraparte al separatismo metodológico que establece que deben de existir dos formas distintas para acercarse a la realidad, es decir, un método para los fenómenos 
naturales y otro para los sociales.

Al mismo tiempo la disyuntiva comentada se resuelve con la propuesta de Posición Teórica en la cual se suscribe la arqueología Ameroibérica que hace que sea explícita frente a cuatro áreas: Valorativa, Epistemológica, Ontológica y Metodológica (cfr GÁNDARA: 2008), lo que permite conocer con certeza sus planteamientos, aspectos que otros posicionamientos no presentan.

Para los arqueólogos Ameroibéricos, la arqueología no se distingue de otras disciplinas de la ciencia social ni por su objeto ni por su método.

De manera que el objeto de estudio de la arqueología es el mismo de todas las disciplinas sociales: la sociedad como un proceso total (no sólo económico), cuya historia está regida por leyes generales que adquieren particularidades en cada etapa de su desarrollo, presentándose como la unidad de la multiplicidad de singularidades en cada caso y momento concreto" (BATE, 1982:17).

Lo específico de la arqueología se debe a las condiciones en que se ha desarrollado tradicionalmente la investigación, conforme al oficio de esta actividad; cuya particularidad es debida a la información empírica (datos arqueológicos) a partir de la cual se infieren las características de las sociedades bajo estudio, y que estos no siempre reflejan las actividades y relaciones sociales que los generaron, pues los objetos arqueológicos han sido afectados por diversos procesos de transformación" (BATE, 1989: 8-9).

Los arqueólogos sociales ameroibéricos parten de que las sociedades del pasado tienen características que pueden ser conocidas y que, por medio de la teorización de estas características, expresadas en su cultura material, se podrán corroborar o refutar los elementos que se propongan con respecto a su realidad. Consideran que se puede explicar a una sociedad como una totalidad concreta. Esto mediante la explicación de los nexos recíprocos entre los aspectos de la realidad que se pretende reflejar en las categorías de formación económico social, modo de vida y cultura (BATE, 1989: 15).

\section{CONCLUSIONES}

De manera resumida se concluye: buscan conocer -los arqueólogos sociales iberoamericanos- la realidad social, esta realidad contiene leyes que son relativas e históricas cuyos cambios son cuantitativos a cualitativos y son debidos por las contradicciones que se dan en la estructura.

\begin{tabular}{|l|l|l|l|l|l|l|} 
(C) Rev. Arqueologia Pública & Campinas, SP & v.9 & No.1(11) $^{\circ}$ & p.3-17 & Jan-Jun/2015 & ISSN 2237-8294
\end{tabular}


Actualmente se siguen discutiendo las categorías con el fin de dar alternativas conceptuales. Es decir, esta teoría si bien retoma conceptos de los "clásicos" (Marx, Lenin, Engels) no las considera como la explicación total a los fenómenos sociales. Así es el caso del concepto de cultura que no se encontraba dentro del paradigma marxista, por lo que se le dio contenido en su papel como categoría general de esta posición.

Otro de los aportes principales es la periodización tridimensional en la cual se establece: La comunidad primitiva de cazadores recolectores pre-tribales. La revolución tribal. La comunidad primitiva tribal. La revolución clasista. La sociedad clasista inicial. El planteamiento de una periodización tridimensional se refiere a que, en tanto están formalizadas teóricamente las interrelaciones entre las diversas dimensiones de la realidad que incluye la categoría de sociedad concreta, es posible desarrollar una periodización que integre, al menos, tres niveles o dimensiones de calidades y cambios de los procesos sociales. Esto es, se pueden distinguir y relacionar las calidades fundamentales de la dimensión de la formación social, de las particulares vías de desarrollo de los modos de vida y de las singularidades características de la cultura. (BATE, 1998a: 7).

Además de los aportes que se han señalado en los párrafos anteriores, la arqueología marxista en México a través de la arqueología Ameroibérica continua vigente y realizando trabajos de investigación, por nombrar algunos ejemplos tenemos la propuesta de la Teoría de lo Biosocial (TERRAZAS, 1992; 2007; BATE y TERRAZAS, 2014), sobre el poblamiento de América (BATE,; 1974; 1982, 2014; TERRAZAS, 2006; 2014), sobre las primeras sociedades en Chiapas y agricultura precerámica (ACOSTA, 1999; 2011; 2014), también sobre el análisis teórico del origen del estado y estudios sobre el patrimonio cultural, su conservación y difusión (GÁNDARA, 1994; 2008; 2102 ), otros más sobre unidades de observación en la teoría de lo observable y sobre los grupos del periodo Postclásico en Chiapas, México (ALFREDO FLORES, 2007) sobre las formas de control, modo de vida, modo de trabajo e identidad en el valle Puebla-Tlaxcala (LAZCANO, 2003; 2005; 2011; 2015), o sobre la aplicación de los contenidos ontológicos de esta posición teórica en la enseñanza media superior (SARMIENTO, 1999; 2012) también sobre complejos artefactuales y económicos y modo de vida (FOURNIER, 2005) y sobre modos de trabajo en el sitio arqueológico de Tula, Hidalgo México (CASTILLO, 2014) sin olvidar diversos estudios que se han concretado en tesis de licenciatura y posgrado. La arqueología Ameroibérica es con certeza una franca alternativa para la explicación del desarrollo y transformación de las sociedades humanas. 
ACOSTA OCHOA, G. Procesos de trabajo determinado. La configuración de modos de trabajo en la cultura arqueológica. Boletín de Antropología Americana, Instituto Panamericano de Geografía e Historia (IPGH) México, n. 35, 1999, p. 5-21.

Milpas en los pantanos. Aspectos de la paleosubsistencia olmeca en La Venta, Tabasco (ca. 1150-400 a. C.). Tesis de Maestría. Facultad de Filosofía y LetrasInstituto de Investigaciones Antropológicas-Universidad Nacional Autónoma de México. México, 2002.

Antecedentes precerámicos de las sociedades del Formativo en el sureste de México. Thule, n. 22, p. 101-110, 2010.

El poblamiento de las regiones tropicales de México hace 12500 años. Anales de Antropología, n. 45 Universidad Nacional Autónoma de México, p. 227-235, 2011.

Señoríos de chiapan y zinacantán: historia y conflicto desde el posclásico tardío hasta el periodo colonial temprano. Posgrado en estudios mesoamericanos, Universidad nacional Autónoma de México, p. 23, 2014.

BATE, L. F. Los primeros poblamientos del Extremo Sur americano. Cuadernos de Trabajo, n. 3, Departamento de Prehistoria. INAH. México. p. 418, 1974.

Relación general entre teoría y método en arqueología. Boletín de Antropología Americana, n. 4, p. 7-54, 1981.

Orígenes de la comunidad primitiva en Patagonia. Ed. Cuicuilco. México. p. $105,1982$.

Hipótesis sobre la sociedad clasista inicial. Boletín de Antropología Americana. No. 9. IPGH. México. p. 47-86, 1984.

El modo de producción cazador recolector o la economía del 'salvajismo. Boletín de Antropología Americana, n. 13, p. 5-31, 1986. 
Notas sobre el materialismo histórico en el proceso de investigación arqueológica. Boletín de Antropología Americana, n. 19. IPGH. México, p. 5-29, 1989. Culturas y modos de vida cazadores recolectores en el poblamiento de América del Sur. Revista de Arqueología Americana, n. 2, p. 89-153, 1990.

Las sociedades cazadoras recolectoras pre-tribales o el 'paleolítico superior' visto desde Sudamérica. Boletín de Antropología Americana, IPGH n. 25, p. 105-155, 1992.

Teoría de la cultura y arqueología. Boletín de Antropología Americana, n. 27 IPGH, p. 75-93, 1993.

Sociedad concreta y periodización tridimensional, Boletín de Antropología Americana, n. 32. IPGH. México, p. 41-56, 1998a.

El proceso de investigación en arqueología. Editorial Crítica. Barcelona. p. 278, 1998b.

Condiciones para el surgimiento de las sociedades clasistas Ponencia presentada en el XIV Coloquio de Historia Canario-Americana, Las Palmas de Gran Canaria. Mecanoescrito, 2000.

BATE, F.; GÁNDARA, M. Cacaxtla: un sitio y muchas preguntas. Mecanoescrito (inédito), p. $172,1981$.

BATE, L.F.; TERRAZAS, A. Apuntes sobre las investigaciones prehistóricas en México y América. En: JIMÉNEZ et al. [Coords.] El Hombre Temprano en América. Primer Simposio Internacional, Colección Científica del INAH, México n. 500, p. 23-48, 2006.

Sobre el modo de reproducción en sociedades pre-tribales. Propuestas para la Arqueología. L. F. Bate, Col. Nuestros Clásicos. ENAH. México. oㅡ 2, p. 317-358, 2014.

BERNAL, I. Historia de la arqueología en México. Porrúa, México, p. 208, 1979. 
BINFORD, W. L. New perpectives in Archaeology. Binford, S. y Binford L., (eds.). Aldine Publishing Company, p. 373, 1968.

For theory Building in Archaeology. Binford L., (ed.). New York, Academic Press. p. 419, 1977.

CASTILLO, B.; STEPHEN, Tula Cuicuilco, vol 12, n. 61, sep-dic, Escuela Nacional de Antropología e Historia, INAH, p. 367-371, 2014.

CHILDE, V.G. Social Evolution, Londres, 1951.

FLORES, J. A. La 'Sociedad Concreta' como contenido esencial del espacio social. Boletín de Antropología Americana, no 43 IPGH, p. 5-60, 2007a.

Patrón de asentamiento e inferencia social. Una propuesta metodológica para la construcción de inferencias sociales. Escuela Nacional de Antropología e Historia, INAH, México, 2007b.

FOURNIER, P. Los Hñähñü del valle del mezquital: Maguey, pulque y alfarería. Escuela Nacional de Antropoolgía e Historia, INAH, México. p. 328, 2005.

GÁNDARA VÁZQUEZ, M. La vieja nueva antropología, parte 1. Boletín de Antropología Americana, №. 2 IPGH, p. 1-47, 1980.

La vieja nueva antropología, parte 2. Boletín de Antropología Americana, №. 3 IPGH, p. 7-71, 1981.

La arqueología oficial mexicana. Causas y efectos. Colección Divulgación. México: Instituto Nacional de Antropología e Historia. p. 243, 1982.

Hacia una teoría de la observación en arqueología. Boletín de Antropología Americana, n. 15 IPGH 1988 p. 5-14, 1988.

Algunas notas sobre el análisis del conocimiento. Boletín de Antropología Americana, n. 22, IPGH, p. 5-20, 1990.

\begin{tabular}{|l|l|l|l|l|l|l|} 
(C) Rev. Arqueologia Pública & Campinas, SP & v.9 & N.1(11) & p.3-17 & Jan-Jun/2015 & ISSN 2237-8294
\end{tabular}


El análisis teórico: aplicaciones al estudio de los orígenes de la complejidad social. Boletín de Antropología Americana, n. 25, IPGH, p. 93-104, 1992a.

La interpretación del patrimonio cultural. Elementos de un modelos holístico para el manejo de recursos culturales en arqueología (guión de exposición), ponencia presentada al Diplomado en Museología, Escuela Nacional de Antropología e Historia, 1992c.

El análisis de posiciones teóricas: aplicaciones a la arqueología social. Boletín de Antropología Americana, n. 27, IPGH, p. 5-20, 1993.

Consecuencias metodológicas de la adopción de una ontología de la cultura: una perspectiva desde la arqueología, In: GONZÁLEZ, J. A. y JESÚS GALINDO C. (coords.): Metodología y cultura: Serie Pensar la Cultura. México: Consejo Nacional para la Cultura y las Artes, p. 67-118, 1994.

El análisis teórico en ciencias sociales: Aplicación a una teoría del origen del Estado en Mesoamérica. Tesis doctoral. Escuela Nacional de Antropología e Historia, INAH, México, 2008.

La divulgación de la arqueología: una aproximación desde el marxismo. Ponencia presentada en el III Congreso de Arqueología Social Ameroibérica, ENAH, ENCRyM, México, 2012.

GÁNDARA, M.; FERNANDO LÓPEZ; IGNACIO RODRÍGUEZ. Arqueología y marxismo en México. Boletín de Antropología Americana n. 11, IPGH, p. 5-17, 1985.

HODDER, I. Interpretación en Arqueología. Corrientes actuales, Crítica/Arqueología, Barcelona, p. 240, 1988.

LAZCANO ARCE, J.C. Exploraciones arqueológicas en Cacaxtla: Plaza de los Tres Cerritos, Antropología e historia del Occidente de México, Sociedad Mexicana de Antropología-Universidad Nacional Autónoma de México, vol. III, México, p. 733-749, 1996. 
Modos de Vida y explotación de recursos naturales en Cacaxtla-Xochitecatl, durante el Epiclásico. Cuicuilco, Revista de la Escuela Nacional de Antropología e Historia, Nueva Época, vol. 5, n.14, Sep-Dic, p. 27-51, 1998a.

La segunda ocupación, Xochitecatl. Gobierno del Estado de Tlaxcala, México, p. 63-76, 1998b.

Modo de vida y explotación de recursos naturales. Ediciones del Cabildo de Gran Canaria, Las Palmas de Gran Canaria, España, 1999

Modo de vida y explotación de recursos naturales en el sitio de Nativitas,Tlaxcala durante el Epiclásico. Tesis de maestría en arqueología, Escuela Nacional de Antropología e Historia, México, 2005.

Estudio etnoarqueológico sobre el modo de trabajo mezcalero durante el periodo formativo medio (400 a. C.) en el sitio arqueológico de Xochitécatl-Nativitas, Tlaxcala. Boletín de Antropología Americana, n. 39, IPGH, p. 157-174, 2003.

Estudio etnoarqueológico de la bebida del mezcal como un modo de trabajo durante el periodo Formativo en el sitio de Xochitecatl-Cacaxtla-Nativitas. Tesis de Doctorado en Antropología. p. 385, Facultad de Filosofía y Letras/Instituto de Investigaciones Antropológicas Universidad Nacional Autónoma de México, 2011.

Identidad étnico arqueológica de los habitantes del valle Puebla-Tlaxcala:

Propuesta Teorica-Metodología. Coordinación de Humanidades, Universidad nacional Autónoma de México, p. 148. En prensa, 2015.

LUMBRERAS, L.G. La arqueología como ciencia social. Ediciones PEISA. Lima p. 187, 1981.

MARX, K. Introducción general a la crítica de la economía política/ 1857. 23를 edición. Siglo veintiuno. México. p. 123, 1991.

MONTANÉ, J. Marxismo y arqueología. Ediciones de Cultura Popular. México. p. 171, 1980. 
Sociedades igualitarias y modos de producción. Boletín de Antropología Americana, n. 3 IPGH, p. 71-87, 1981.

PIÑA CHAN, R. Historia, arqueología y arte prehispánico. Fondo de Cultura Económica, México, 1970.

SANOJA, M. Siete temas de debate en Arqueología Social. Cuadernos de Antropología. Universidad de Costa Rica. San José, 1982.

La inferencia en Arqueología Social. Boletín de Antropología Americana, n. 10, IPGH, p. 35-44, 1984.

SARMIENTO, G. Las sociedades cacicales agrícolas. Boletín de Antropología Americana, n. 13, IPGH, p. 33-64, 1986.

Las primeras sociedades jerárquicas. Colección científica del INAH. México, 1992.

Tribus y cacicazgos arqueológicos: una discusión acerca del origen de la estratificación social. Boletín de Antropología Americana, n. 27 IPGH, p. 95-108, 1993.

La arqueología Social y la enseñanza de la historia. Boletín de Antropología Americana, n. 34, IPGH, p. 3-15, 1999.

Elementos de las sociedades clasistas iniciales para la enseñanza del capitalismo del siglo $\mathbf{X X}$, ponencia presentada en el III Congreso de Arqueología Ameroibérica Ciudad de México, 2012.

TERRAZAS, A. Bases para la elaboración de una teoría paleoantropológica. Boletín de Antropología Americana, n. 25, IPGH, p. 5-18, 1992.

Teorías de la complejidad, hibridación y el estudio de la evolución humana. Boletín de Antropología Americana, n. 27, IPGH, p. 109-123, 1993. 
Los procesos de hominización desde una teoría de la coevolución humana.

Boletín de Antropología Americana, n. 35, IPGH, p. 23-36, 1999.

Teoría de coevolución humana. Tesis de Maestría. Facultad de Filosofía y Letras. UNAM. México, 2001.

Cultura, modos de vida y evolución humana: relaciones categoriales. Boletín de Antropología Americana, n. 35 IPGH, p. 5-33, 2006.

TRIGGER, B.; CHILDE, G. Revolutions in archaeology New York, Columbia University Pres, 1980.

VARGAS, I. Definición de conceptos para una arqueología social. Fonseca ed., p. 136150, 1984.

Modo de vida: categoría de las mediaciones entre formación social y cultura.

Boletín de Antropología Americana, n. 12, IPGH, p. 5-16, 1985.

VELOZ MAGGIOLO, M. Arqueología de la vida cotidiana. Boletín de Antropología Americana, n. 10, IPGH, p. 5-21, 1984a.

La arqueología de la vida cotidiana. Matices, historia y diferencias. Fonseca p. 92-111, 1994.

Algunas notas sobre la categoría de modo de trabajo. Gens, vol. 3, n. 1, p. 40-49, 1987. 